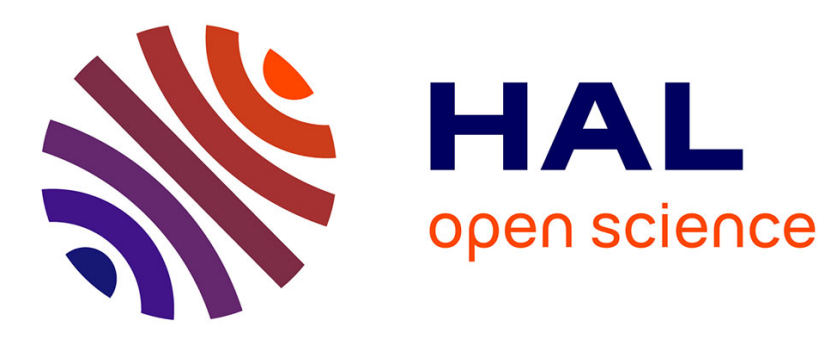

\title{
Defects in CaF2 caused by long-time irradiation and their response to annealing
}

\author{
Vojtech Vlcek, Jakub Cizek, Jan Drahokoupil, Jan Valenta, Nobuyoshi \\ Miyajima, Roman Skala
}

\section{- To cite this version:}

Vojtech Vlcek, Jakub Cizek, Jan Drahokoupil, Jan Valenta, Nobuyoshi Miyajima, et al.. Defects in CaF2 caused by long-time irradiation and their response to annealing. Philosophical Magazine, 2010, 90 (20), pp.2749-2769. 10.1080/14786431003745385 . hal-00596600

\section{HAL Id: hal-00596600 https://hal.science/hal-00596600}

Submitted on 28 May 2011

HAL is a multi-disciplinary open access archive for the deposit and dissemination of scientific research documents, whether they are published or not. The documents may come from teaching and research institutions in France or abroad, or from public or private research centers.
L'archive ouverte pluridisciplinaire HAL, est destinée au dépôt et à la diffusion de documents scientifiques de niveau recherche, publiés ou non, émanant des établissements d'enseignement et de recherche français ou étrangers, des laboratoires publics ou privés. 


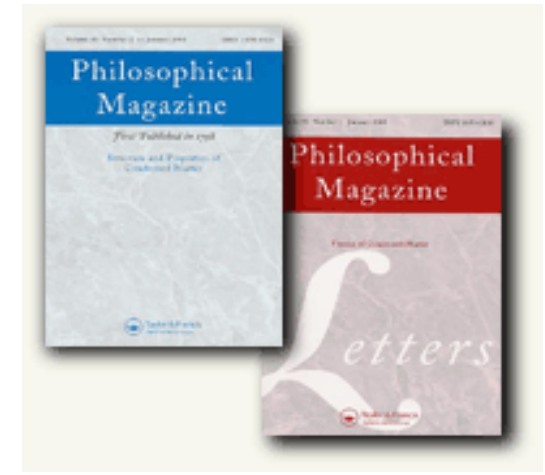

\section{Defects in CaF2 caused by long-time irradiation and their response to annealing}

\begin{tabular}{|c|c|}
\hline Journal: & Philosophical Magazine \& Philosophical Magazine Letters \\
\hline Manuscript ID: & TPHM-09-Oct-0449.R1 \\
\hline Journal Selection: & Philosophical Magazine \\
\hline $\begin{array}{r}\text { Date Submitted by the } \\
\text { Author: }\end{array}$ & 29-Jan-2010 \\
\hline Complete List of Authors: & $\begin{array}{l}\text { Vlcek, Vojtech; Bayerisches Geoinstitut; Faculty of Sciences, } \\
\text { Institute of Geochemistry, Mineralogy and Mineral Resources } \\
\text { Cizek, Jakub; Faculty of Mathematics and Physics } \\
\text { Drahokoupil, Jan; Institute of Physics } \\
\text { Valenta, Jan; Faculty of Mathematics and Physics } \\
\text { Miyajima, Nobuyoshi; Bayerisches Geoinstitut } \\
\text { Skala, Roman; Institute of Geology }\end{array}$ \\
\hline Keywords: & defects, microstructure, photoluminescence, TEM, X-ray diffraction \\
\hline Keywords (user supplied): & CaF2, fluorite, PAS \\
\hline
\end{tabular}

\section{今scholarONE \\ Manuscript Central}




\title{
Defects in $\mathrm{CaF}_{2}$ caused by long-time irradiation and their response to annealing
}

\author{
Vojtěch Vlček ${ }^{1,2}$, Jakub Č́́žek $^{3}$, Jan Drahokoupil $^{4,5}$, Jan Valenta ${ }^{6}$,
} Nobuyoshi Miyajima², Roman Skála ${ }^{1,7}$

1) Faculty of Sciences, Charles University in Prague, Albertov 6, CZ - 12000, Prague

2, Czech Republic

2) Bayerisches Geoinstitut, Universität Bayreuth, D-95440, Bayreuth, Germany

3) Faculty of Mathematics and Physics, Charles University in Prague,

V Holešovičkách 2, CZ-18000, Praha 8, Czech Republic

4) Institute of Physics of the ASCR, v. v. i., Na Slovance 2, CZ-182 21 Prague 8, Czech Republic

5) Faculty of Nuclear Sciences and Physical Engineering, Czech Technical

University, Trojanova 13, CZ-120 00, Prague 2, Czech Republic

6) Faculty of Mathematics and Physics, Charles University in Prague,

Ke Karlovu 3, CZ-12000, Praha 2, Czech Republic

7) Institute of Geology of the ASCR, v. v. i., Rozvojová 269, CZ-16500 Prague 6, Czech Republic

corespondence author: Vojtěch Vlček vojtech.vlcek@uni-bayreuth.de

\begin{abstract}
Samples of $\mathrm{CaF}_{2}$ irradiated for millions of years in nature were studied by several methods: X-Ray Diffraction, Positron Annihilation Spectroscopy (PAS),

Photoluminescence Spectroscopy (PLS), and Transmission Electron Microscopy (TEM). It was shown that the unexpectedly high density of radiation-induced defects present in the fluorite structure (documented by TEM) causes significant micro-strains. Even annealing up to $450{ }^{\circ} \mathrm{C}$ cannot completely remove these micro-strains which are stabilised by impurities. The PAS and subsequent theoretical calculations revealed the behaviour of the defects during heating. The PL spectra of irradiated fluorite were interpreted as well.
\end{abstract}

Keywords: $\mathrm{CaF}_{2}$, fluorite, microstructure, defects, Positron Annihilation Spectroscopy, Photoluminescence Spectroscopy, Transmission Electron Microscopy, X-ray Diffraction

\section{Introduction}

Radiation-induced defects in fluorite $\left(\mathrm{CaF}_{2}\right)$ structure were investigated only in artificially irradiated samples in the recent studies (e.g., Refs. [1-4]). However, the response of the structure to a long-time irradiation (of the order of million years) is essential for understanding the processes of formation and the stability of defect centres. These recent studies showed that the radiation damage of fluorite should reach a saturation level and then there should be a dynamic balance of creation and 
annihilation of the centres resulting in minimum strains within the lattice.

Understanding how the fluorite structure responses to a long-term irradiation is

important for its potential use under conditions of prolonged exposition to radiation in applications such as containment of radioactive waste (proposed in Ref. [2]), special optics or applications in electrotechnics (e.g. Ref. [5]). As a consequence, we chose the natural samples of fluorite to evaluate effect of the long-time irradiation on $\mathrm{CaF}_{2}$ structure. The microstructure analysis from X-ray powder diffraction data, Positron Annihilation Spectroscopy (PAS), Photoluminescence Spectroscopy (PLS) and Transmission Electron Microscopy (TEM) were used to decipher the behaviour of fluorite under prolonged radiation.

\section{Experimental methods and sample description}

\subsection{Samples}

A natural $\mathrm{CaF}_{2}$ sample from Kletno (Poland) was exposed to radiation emitted by surrounding uraninite $\left(\mathrm{UO}_{2}\right)$ for millions of years. It has a dark purple colour and dim surface. This sample was assumed to display the highest degree of irradiation damage. Fluorite from Vlastějovice (Czech Republic) was irradiated by allanite (Cesilicate). The activity of this mineral is several times lower in comparison to uraninite. Hence, the sample from Vlastějovice was assumed to represent a low-irradiated $\mathrm{CaF}_{2}$. A non-irradiated fluorite sample from the locality Jílové u Děčína (Czech Republic) and a synthetic standard (Suprapur, Merck) were used as reference materials.

\subsection{X-ray diffraction}

X-ray powder diffraction patterns were collected with a PANalytical X'Pert Pro diffractometer equipped with an $\mathrm{X}^{\prime}$ Celerator position-sensitive detector and a secondary graphite monochromator (Institute of Physics, Academy of Sciences of the Czech Republic). Data were step-scanned over the range from $10^{\circ}$ to $150^{\circ} 2 \Theta$ with 
$0.05^{\circ}$ step size and $300 \mathrm{~s}$ counting time per step. Cobalt tube was operated at $40 \mathrm{kV}$ voltage and $30 \mathrm{~mA}$ current.

The naturally irradiated fluorite sample from Kletno annealed up to $450{ }^{\circ} \mathrm{C}$ was subsequently X-ray irradiated on conventional X-ray source MIKROMETA (Faculty of Science, Charles University in Prague) with unfiltered radiation from $\mathrm{Cu}$ tube operated at $40 \mathrm{kV}$ and $30 \mathrm{~mA}$.

The diffraction peak parameters were fitted using Rietveld refinement procedure with Le-Bail fit as implemented in the HighScore software (PANalytical) . The Williamson-Hall plot (described in Ref. [6]) is used to visualize the difference between crystallite size and a micro-strain peak broadening.

\subsection{PAS}

$\mathrm{A}^{22} \mathrm{Na}_{2} \mathrm{CO}_{3}$ positron source with activity of $1.5 \mathrm{MBq}$ deposited on a $2 \mu \mathrm{m}$ thick mylar foil was used in PAS measurements. The source was placed in the centre of a small cylindrical chamber with a diameter of $10 \mathrm{~mm}$ and height of $5 \mathrm{~mm}$. Subsequently, the chamber was completely filled with the sample powder and closed. Dimensions of the chamber ensure that virtually all positrons are stopped inside the chamber and, thereby, annihilate in the studied powder.

Positron-lifetime measurements were performed on a digital spectrometer described in Refs. $[7,8]$. The spectrometer is equipped with $\mathrm{BaF}_{2}$ scintillators and fast photomultipliers Hamamatsu H3378. Detector pulses are directly digitized using a couple of 8-bit ultra-fast digitizers Acqiris DC 211 with sampling frequency of 4 GHz. Analysis of digitized pulses and construction of positron-lifetime spectrum is performed off-line using so called integral true constant fraction technique described in Ref. [9]. The spectrometer exhibits excellent time resolution of 145 ps (full width at half-maximum $(\mathrm{FWHM}){ }^{22} \mathrm{Na}$ ). At least $10^{7}$ positron annihilation events were 
accumulated in each positron lifetime spectrum. Decomposition of positron-lifetime spectra into exponential components were performed using a maximum likelihood procedure described in Ref. [10]. The source contribution to positron-lifetime spectra consisted of two weak components with lifetimes of $\sim 368 \mathrm{ps}$ and $\sim 1.5 \mathrm{~ns}$ and corresponding intensities of $\sim 8 \%$ and $\sim 1 \%$. These components represent a contribution of positrons annihilated directly in $\mathrm{Na}_{2} \mathrm{CO}_{3}$ source and the covering mylar foils.

Coincidence Doppler broadening (CDB) studies were carried out using a spectrometer [11] equipped with two high purity Ge detectors. The overall energy resolution of the CDB spectrometer is $(1.02 \pm 0.01) \mathrm{keV}$ at $511 \mathrm{keV}$. At least $10^{8}$ annihilation events were collected in each of two-dimensional $\gamma$-ray energy spectra, which were subsequently reduced into two one-dimensional cuts representing the resolution function of spectrometer and Doppler broadened annihilation profile. In this paper $\mathrm{CDB}$ results are presented as ratio curves with respect to a well annealed bulk $\mathrm{Mg}(99.99 \%)$ reference specimen

Theoretical calculations of positron parameters were performed from the first principles using an approach based on the density functional theory. Positron wave function was calculated within so-called conventional scheme employing the atomic superposition (ATSUP) method [12]. Electron-positron correlation was treated within local density approximation (LDA) using the scheme developed by Boronski and Nieminen [13] with the correction [14] for incomplete positron screening with high frequency dielectric constants $\varepsilon_{\infty}=6.8$ [15]. A cubic structure with lattice parameter $a$ $=5.46305 \AA$ [16] was adopted for $\mathrm{CaF}_{2}$. A supercell approach was used for calculations of positron parameters for $\mathrm{CaF}_{2}$ crystal containing defects. The calculations were performed on 768 atom-based supercells. Vacancies or vacancy 
agglomerates were created simply by removing the appropriate number of atoms from the supercell.

The high momentum part (HMP) of momentum distribution of electrons that annihilated positrons was performed using ATSUP-based approach according to the scheme described in Refs. $[17,18]$. Electron-positron correlation was treated using LDA approach $[13,14]$ and also by generalized gradient approximation (GGA) scheme developed by Barbiellini et al. [19,20]. Only the contribution from positrons annihilated by localized core electrons were considered in the calculations. Hence, comparison of calculated HMP curves with experiment is meaningful only in the high momentum range, $p>\left(10 \times 10^{-3}\right) m_{0} c$, where contribution of positrons annihilated by core electrons dominates. The following orbitals were considered as core electrons and included in the calculations of HMP curves: $\mathrm{Ca}: 1 s^{2}, 2 s^{2}, 2 p^{6}, 3 s^{2}, 3 p^{6}, \mathrm{~F}$ : $1 s^{2}, 2 s^{2}, 2 p^{5}, \mathrm{Mg}: 1 s^{2}, 2 s^{2}, 2 p^{6}$.

The final one-dimensional HMP curve, which can be compared to the experimental CDB spectrum is obtained by summing up the contributions of the core states of all atoms in the system and integrating over the high-momentum tail. In order to compare the calculated HMP curves to experimental CDB spectra, they have to be properly normalized. The areas of the experimental CDB spectra were scaled to unity, while the areas below the theoretical HMP curves were set equal to $\lambda_{\text {core }} / \lambda$, where $\lambda_{\text {core }}$ is the annihilation rate with all core electrons of the system, while $\lambda$ is the total annihilation rate, i.e. the inverse of positron lifetime. In order to mimic the effect of the finite resolution of the experimental setup, the theoretical HMP curves were convoluted with a Gaussian with FWHM of $\left(4.0 \times 10^{-3}\right) m_{0} c$. 


\subsection{PLS}

The high- and low-irradiated fluorite and the reference sample of synthetic $\mathrm{CaF}_{2}$ were investigated by photoluminescence micro-spectroscopy. In addition to that also the high-irradiated sample annealed to $450{ }^{\circ} \mathrm{C}$ was investigated after exposure to X-rays. The PL emission was collected by the inverted microscope Olympus IX-71 with 20x magnification objective lens and detected with the liquid-nitrogen cooled BI-CCD camera attached to the imaging spectrometer Acton SpectraPro 2150i. The data were measured at room temperature. PL was excited by a diode laser emitting at $405 \mathrm{~nm}$. Several measurements were made on different positions of each sample in order to obtain reasonable statistics. The data were fitted by Fityk software [21] using split Gaussian function, which refines peak half-widths separately.

\subsection{TEM}

Powdered fluorite samples (from Kletno, Vlastějovice and synthetic $\mathrm{CaF}_{2}$ ) were placed onto TEM copper grids coated with carbon holey films. Microscope used to study the samples was a Philips CM 20 FEG (at the Bayerisches Geoinstitut, Universität Bayreuth, Germany) operated at $200 \mathrm{kV}$ voltage. The samples were imaged under bright field, dark field, and weak-beam dark-field conditions. Also, high-resolution TEM images were acquired. Selected area electron diffraction was used to define orientation of the samples. In order to investigate existence of some impurities, energy-dispersive X-ray spectra were also collected with $60 \mathrm{sec}$ live time.

\section{Results and discussion}

\subsection{X-ray diffraction}

The diffraction peaks of the irradiated sample are broadened mainly due to micro-strain that is caused by defects and lattice deformations; the domain size broadening has negligible contribution. The diffraction patterns were collected during in-situ heating at different temperatures to obtain information about the structure 
recovery caused by annealing. Subsequent peak-broadening analysis using

Williamson-Hall method [6] confirmed the expected decrease of micro-strain values. The data plotted in Williamson-Hall graph (Fig. 1) shows that the main recovery process is started at temperatures higher than $300{ }^{\circ} \mathrm{C}$. To determine possible slow kinetics at lower temperature the several measurements were done at $300{ }^{\circ} \mathrm{C}$ (total heating lasted 8 hours), however no change of micro-strain was observed.

The annealed sample (up to $450{ }^{\circ} \mathrm{C}$ ) became colourless after the experiment, yet some micro-strains remained. We assume that some defects persist and are not affected by heating. It should be noted that the reference samples from Jílové and the synthetic $\mathrm{CaF}_{2}$ showed also non-zero values of micro-strain. Nevertheless, these micro-strain values are substantially lower than those observed in the annealed and Xray irradiated samples.

Another interesting feature noted in the annealed samples is a colour change from colourless to purple upon irradiation by the X-ray beam during the XRD study. The stability of colouration depends on the time of X-ray irradiation. After a short irradiation (about 1 hour) the colour dissipates in about three days; however after irradiation that took more than 500 hours the colour is stable. X-ray irradiation does not affect the microstructure characteristics of the sample (no peak-broadening was observable in diffraction pattern). This confirms the different character of the colour centers and the defects causing microdeformation.

\subsection{PAS}

\subsubsection{Theoretical calculations}

First principles calculations of positron characteristics were performed in order to identify defects in $\mathrm{CaF}_{2}$ samples. Table 1 shows calculated positron lifetimes for various positron states in $\mathrm{CaF}_{2}$ crystal. Calculated positron density in (110) plane 
for a perfect defect-free $\mathrm{CaF}_{2}$ crystal is plotted in Fig. 2 A. Positron in a perfect $\mathrm{CaF}_{2}$ crystal is delocalized in the lattice in the form of modulated Bloch-like wave.

Calculated bulk positron lifetime in a perfect $\mathrm{CaF}_{2}$ crystal is $171.5 \mathrm{ps}$.

Figure $2 \mathrm{~B}$ shows calculated positron density in $\mathrm{CaF}_{2}$ containing an $\mathrm{F}$ vacancy. Although there is a slight enhancement of positron density in the vicinity of F-vacancy, there is still a significant probability to find positron elsewhere. Hence, Fvacancy is too shallow trap incapable to confine positron. This is confirmed by positron lifetime, which approaches the bulk positron lifetime in $\mathrm{CaF}_{2}$ and also by a negligible positron binding energy to F-vacancy, see Table 1.

On the other hand, Ca-vacancy is a deep positron trap. Fig. $2 \mathrm{C}$ shows that positron is completely localized in Ca-vacancy. Calculated lifetime of positron trapped in Ca-vacancy is 225.9 ps and positron binding energy to this defect is 1.68 $\mathrm{eV}$.

Thus, theoretical calculations clearly demonstrated that F-vacancies as very shallow traps are "invisible" to positrons. On the other hand, Ca-vacancies as strong traps can be undoubtedly detected by PAS.

It is known that $\mathrm{F}$-vacancies produced in $\mathrm{CaF}_{2}$ by irradiation aggregate and form fluorine voids [22-25]. This process leads to formation of metallic Ca inclusions in $\mathrm{CaF}_{2}$ where fluorine voids occur and only $\mathrm{Ca}$ atoms remain in their sites. Due to this reason, it is important to examine the possibility of positron trapping in aggregates of F-vacancies. Figure 3 shows results of the first principle calculations of positron parameters for F-vacancy aggregates of various sizes. One can see in Fig. 2 that positron lifetime and positron binding energy to an aggregate of F-vacancies increases with increasing number of F-vacancies (i.e., increasing size of fluorine void). The calculated positron density for a $\mathrm{CaF}_{2}$ crystal containing F-divacancy is 
plotted in Fig. 4 A. Similarly to F-vacancy also F-divacancy is too shallow trap to confine positron. This is demonstrated not only by absence of positron localization, but also by calculated positron lifetime, which is close the bulk positron lifetime in perfect $\mathrm{CaF}_{2}$ and very small positron binding energy to F-divacancy.

A remarkable increase of positron binding energy occurs for F-tetravacancy, see Fig. 3 B. Calculated positron density for $\mathrm{a} \mathrm{CaF}_{2}$ crystal containing F-tetravacancy is plotted in Fig. 4 B and shows a significant increase of positron localization. Hence, F-tetravacancy becomes capable of positron trapping and can be detected by PAS. Even larger aggregates of F-vacancies are yet deeper traps characterized by a longer positron lifetime and higher positron binding energy, (Fig. 3). Figure 5 A shows calculated positron density for an agglomerate of $8 \mathrm{~F}$-vacancies. One can see that positron is fully localized and lifetime of positrons trapped at this defect is comparable to that of positron trapped in Ca-vacancy (Fig. 3 A).

Calculated positron characteristics for $\mathrm{a} \mathrm{CaF}_{2}$ supercell with all $\mathrm{F}$ atoms removed represents an extreme case and simulates a very large fluorine void; it is plotted in Fig. 5 B. The figure illustrates that positron is delocalized inside the fluorine void and is located mostly in the empty sites in fluorine sub-lattice. Lifetime of positron delocalized in very large fluorine void is $301.9 \mathrm{ps}$ and positron binding energy is $1.44 \mathrm{eV}$.

\subsubsection{Positron lifetime spectroscopy}

The reference non-irradiated $\mathrm{CaF}_{2}$ powder exhibits a two-component positron lifetime spectrum. The shorter component with lifetime $\tau_{1}=(110 \pm 10) \mathrm{ps}$ and relative intensity $I_{l}=(41 \pm 1) \%$ can be attributed to free, delocalized positrons. The longer component with lifetime $\tau_{2}=(322 \pm 2)$ ps and relative intensity $I_{2}=(59 \pm 1) \%$ is a contribution of positrons trapped at defects. The lifetime $\tau_{2}$ of this component is 
longer then lifetimes calculated for aggregates of F-vacancies (Fig. 3 A). It is even longer than the upper limit for F-vacancy aggregates, i.e., positron lifetime of $302 \mathrm{ps}$ calculated for a large fluorine void. Hence, the longer component in positron lifetime spectrum of reference $\mathrm{CaF}_{2}$ powder represents a contribution of positrons trapped at larger defects (voids) containing not only F-vacancies, but also Ca-vacancies.

In the frame of the two-state simple trapping model [26] the quantity

$$
\tau_{f}=\left(\frac{I_{1}}{\tau_{1}}+\frac{I_{2}}{\tau_{2}}\right)^{-1}
$$

equals to the bulk positron lifetime

$$
\tau_{f} \equiv \tau_{B}
$$

Equations $(1,2)$ are frequently used to check the consistency of spectrum decomposition with the two-state simple trapping model. For the reference $\mathrm{CaF}_{2}$

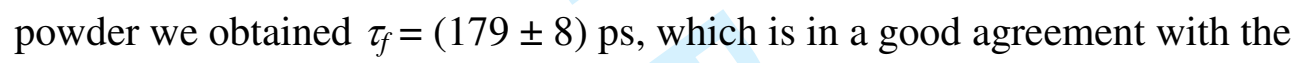
calculated bulk positron lifetime in a perfect $\mathrm{CaF}_{2}$ crystal shown in Table 1 . This confirms that assumptions of two-state simple trapping model (i.e., a single type of uniformly distributed defects) are fulfilled in the case of virgin $\mathrm{CaF}_{2}$ powder. Note that positron annihilations studies of $\mathrm{CaF}_{2}$ crystals were performed by angularcorrelation [27] but no positron lifetime investigations of $\mathrm{CaF}_{2}$ crystals have been performed so far to our best knowledge.

The irradiated natural $\mathrm{CaF}_{2}$ powder from Kletno exhibits two-component positron lifetime spectrum. Both lifetimes $\tau_{1}, \tau_{2}$ of these components are longer than the bulk positron lifetime in $\mathrm{CaF}_{2}$. Thus, both these components represent a contribution of positrons trapped at defects. The longer component exhibits lifetime $\tau_{2}$ $=(335 \pm 4) \mathrm{ps}$, which is comparable with the lifetime $\tau_{2}$ measured on the reference powder. Hence, similarly to the reference powder, the longer component in the irradiated $\mathrm{CaF}_{2}$ can be attributed to positrons trapped at larger voids containing both 
F-vacancies and Ca-vacancies. On the other hand, the shorter component with lifetime $\tau_{l}=(197 \pm 1)$ ps represents a contribution of positrons trapped at new defects created by irradiation. It is well known that agglomerates of F-vacancies are formed in irradiated $\mathrm{CaF}_{2}$ [22-25]. Indeed, the lifetime $\tau_{1}$ corresponds to the calculated lifetime of positrons trapped at an agglomerate of 4 F-vacancies (Fig. 3 A).

The irradiated $\mathrm{CaF}_{2}$ powder from Kletno was subsequently subjected to isochronal annealing. The mean positron lifetime is

$$
\tau_{\text {mean }}=\sum_{i} I_{i} \tau_{i}
$$

where the centre of mass of positron-lifetime spectrum is a robust single parameter, which is not influenced by mutual correlations of fitted parameters. Figure 6 shows dependence of the mean positron lifetime on the annealing temperature for irradiated $\mathrm{CaF}_{2}$ powder from Kletno. There is a strong increase of $\tau_{\text {mean }}$ in the temperature range from 200 to $300^{\circ} \mathrm{C}$ indicating a change of defect structure. Finally, above $300^{\circ} \mathrm{C}$, the mean lifetime decreases.

More information can be obtained from decomposition of positron lifetime spectra. At all annealing temperatures positron-lifetime spectra of irradiated $\mathrm{CaF}_{2}$ are well fitted by two components. Lifetimes of these two components are plotted in Fig. $7 \mathrm{~A}$ as a function of annealing temperature whereas Fig. 7 B shows temperature dependence of the intensity $I_{2}$ of the longer component.

Lifetime $\tau_{l}$ of positrons trapped at F-vacancy agglomerates gradually increases with annealing temperature (inset in Fig. 7 A) indicating increasing size of the agglomerates. The intensity $I_{l}$ of positrons trapped at F-vacancy agglomerates plotted in Fig. $7 \mathrm{~B}$ increases remarkably after annealing above $300^{\circ} \mathrm{C}$. This behaviour indicates that agglomeration of irradiation-induced single F-vacancies or very small F-vacancy clusters occurs at temperatures $T \geq 300^{\circ} \mathrm{C}$. Theoretical calculations in 
section 3.2.1 demonstrated that isolated F-vacancies or very small F-vacancy agglomerates containing less than 4 F-vacancies cannot be detected by PAS. However, larger agglomerates containing at least 4 F-vacancies are capable of positron trapping and can be detected by PAS. Hence, agglomeration of isolated Fvacancies or very small F-vacancy clusters into larger agglomerates, which takes place at temperatures $T \geq 300^{\circ} \mathrm{C}$, enhances positron trapping to these defects, which is reflected by an increase of intensity $I_{1}$. This is accompanied by a gradual increase of lifetime $\tau_{l}$ of this component due to increasing average size of F-vacancy agglomerates. The lifetime $\tau_{2}$ of the longer component increases after annealing at $300^{\circ} \mathrm{C}$. This could be due to $\mathrm{F}$ interstitials ( $H$-centres) which become mobile at $300^{\circ} \mathrm{C}$ and form fluorine bubble-like defects (described e.g. in Ref. [22]) in the sample. Positrons trapped at these fluorine bubbles contribute to the longer component and causes an increase of lifetime $\tau_{2}$.

\subsubsection{Coincidence Doppler Broadening}

Figure 8 shows calculated HMP profiles for a perfect $\mathrm{CaF}_{2}$ crystal and reference defect-free pure $\mathrm{Mg}$. The experimental curves for a reference non-irradiated $\mathrm{CaF}_{2}$ powder and a well annealed bulk $\mathrm{Mg}$ are plotted in the figure as well. It is clear that the curves calculated using GGA scheme are in better agreement with experiment than curves calculated using LDA approach. This is due to well known fact that LDA overestimates positron annihilations with core electrons [21]. Due to this reason only the curves calculated using GGA scheme will be considered in the further discussion. As was explained in section 3.2.1, only localized core electrons which retain their atomic character are considered in the calculations of HMP profiles. Low momentum valence electrons were not included in the calculations. Therefore, comparison of calculated curves with experiment is meaningful only in the high momentum range $p$ 
$>10 \times 10^{-3} m_{0} c$, where positron annihilations with localized core electrons dominate. Indeed, one can see in Fig. 8 that experimental curves for reference $\mathrm{CaF}_{2}$ and $\mathrm{Mg}$ are well reproduced by theoretical calculations in the high momentum range $p>10 \times 10^{-3}$

$m_{0} c$.

The contributions of various electron orbitals to the calculated HMP profile for a perfect $\mathrm{CaF}_{2}$ crystal are plotted in Fig. 9. From comparison of experimental profile with theoretical calculations, it is clear that positrons are annihilated mostly by F electrons. This is not surprising because there is an attractive Coulomb interaction between positron and $\mathrm{F}$ anions. Thus, in a perfect $\mathrm{CaF}_{2}$ crystal the overlap of positron density with $\mathrm{F}$ anions is significantly larger than with Ca cations, see Fig. 2 A.

Figure 10 shows the ratio curve (related to $\mathrm{Mg}$ reference) for the reference non-irradiated $\mathrm{CaF}_{2}$ powder and naturally irradiated $\mathrm{CaF}_{2}$ sample from Kletno in the as-received state and after annealing to various temperatures. The ratio curves exhibit a sharp peak located at $p \sim\left(9 \times 10^{-3}\right) m_{0} c$. This is mainly due to contribution of positrons annihilated by fluorine $2 p$ electrons. The second important feature is a broad peak at $p \sim\left(40 \times 10^{-3}\right) m_{0} c$, which represents a contribution of positrons annihilated by fluorine $s$-electrons.

The irradiated $\mathrm{CaF}_{2}$ sample is characterized by a decrease in amplitudes of both peaks in the ratio curves (Fig. 10). This confirms that the contribution of positrons annihilated by fluorine electrons is reduced in the irradiated sample. This is in accordance with formation of F-vacancy aggregates detected by positron-lifetime spectroscopy. Contrary to free positrons delocalized in perfect $\mathrm{CaF}_{2}$ crystal, positrons localized in F-vacancy aggregates (containing at least 4 F-vacancies) are annihilated mostly by Ca-electrons because fluorine atoms are missing in F-vacancy aggregates. 
Hence, an increase in positron trapping in F-vacancy aggregates causes a decrease in fraction of positrons annihilated by F-electrons.

This effect can be seen also on the calculated HMP curves plotted in Fig. 11. Clearly, the calculated ratio curves for positrons trapped at F-vacancy agglomerates are lower than the curve for a perfect $\mathrm{CaF}_{2}$ crystal. This is due to reduced contribution of positrons annihilated by F-electrons. The ratio curve for F-vacancy agglomerate containing $8 \mathrm{~F}$-vacancies is located below the curve for agglomerate containing 4 vacancies because the contribution of positrons annihilated by F-electrons decreases with increasing size of the agglomerate.

On the other hand, the calculated ratio curve for positrons trapped in Cavacancy is situated above the curve for a perfect $\mathrm{CaF}_{2}$ because $\mathrm{F}$-atoms occupy the nearest neighbour sites of Ca-vacancy. Hence, there is relatively high probability that it will be annihilated by F-electron, while the probability to be annihilated by Caelectron is negligible.

With increasing temperature the fraction of positrons annihilated by Felectrons firstly decreases due to increasing size of F-vacancy agglomerates (Fig. 10 B). The lowest contribution of the positrons annihilated by F-electrons was found after annealing at $100^{\circ} \mathrm{C}$. Annealing to temperatures above $200^{\circ} \mathrm{C}$ leads to an increase of fraction of positrons annihilated by F-electrons because positrons become trapped at fluorine bubbles, i.e., the fraction of positrons annihilated by F-electrons increases. This enhancement of fraction of positrons annihilated by F-electrons agrees with increase of lifetime $\tau_{2}$ observed by positron-lifetime spectroscopy (Fig. 7 A) and explained by formation of fluorine bubbles. 


\subsection{PLS}

The detected PL spectra revealed a distinct behaviour of irradiated and nonirradiated fluorites. Six different emission bands with peaks at about 431, 479, 514, 587,644 , and $720 \mathrm{~nm}$ were observed. They are labelled $\mathrm{E}_{1}$ to $\mathrm{E}_{6}$, respectively, and they are listed in Table 3. However the natural reference fluorite sample from Júlové shows no emission bands, this confirms absence of impurities or luminescent defects. The $E_{2}$ and $E_{5}$ bands are present in the synthetic reference sample and some irradiated samples and seem to be unaffected by heating or X-ray irradiation. Therefore these bands cannot be related to radiation-induced defects. We assigned the $\mathrm{E}_{2}$ emission peak (corresponding to $2.59 \mathrm{eV}$ ) to oxygen centres (e.g. Ref. [28]).

For the irradiated samples the $\mathrm{E}_{1}, \mathrm{E}_{3}$ and $\mathrm{E}_{6}$ emission bands are characteristic (Fig. 12). The first one has the highest intensity and low FWHM (i.e., narrow energy distribution). It corresponds to energy of $2.88 \mathrm{eV}$ and it is not affected by the annealing or further $\mathrm{X}$-ray irradiation. The $\mathrm{E}_{3}$ is a broad emission peak corresponding to energy of $2.41 \mathrm{eV}$. Its position is not affected by the annealing. The $\mathrm{E}_{6}$ has a broad FWHM and its centre corresponds to energy of $1.72 \mathrm{eV}$. This emission is not present in the annealed samples which became colourless upon annealing but the $\mathrm{E}_{6}$ emission reappears again in the samples irradiated by X-ray after being annealed.

The $\mathrm{E}_{1}$ emission band can be assigned either to $F$-centres or their clusters or to the impurities, which cause emissions slightly shifted to lower wavelengths. This effect is discussed in previous studies for, e.g., $\mathrm{Zn}^{+}$, see [4], or $\mathrm{Eu}^{2+}$, see [29] Since impurities are common in all natural samples both impurities and $F$-centers can be expected to contribute to the $\mathrm{E}_{1}$ emission band. Defect centres in natural samples could be bound to the foreign atoms in the structure. This binding makes the defects more stable and resistant to heating. However, the exact character of the substituents 
effect and an additional study would be necessary to get the desired information. As

the $E_{3}$ emission has behaviour similar to $E_{1}$ it probably represents the same type of luminescence centres. The interpretation of the $\mathrm{E}_{6}$ emission band seems to be more complicated as it is influenced by heating and X-ray irradiation; it will be discussed later.

In the annealed samples the additional $\mathrm{E}_{4}$ emission appears; corresponds to energy of $2.11 \mathrm{eV}$. However, it is placed in the region of a broad absorption band of $F$ - or $H$-centres, see [4]. We suppose that the $\mathrm{E}_{4}$ emission is present in irradiated sample before heating but it is absorbed within the sample. The small emission bands of different peak shape and very low FWHM visible on Figure 12 B are most likely emissions of impurities. As they should not be affected by heating, their presence only in the spectrum of annealed $\mathrm{CaF}_{2}$ indicates that the ( $F$ and $H$-centers) absorption band disappeared.

The annealed samples of fluorite when X-ray irradiated exhibit the same PL spectra as untreated samples. As the XRD results showed that no new structural defects are formed (described in section 3.1) we assume that the $\mathrm{E}_{6}$ emission is connected with some centres, which cannot be detected by XRD. The $F$-centers, which are known to be present in the irradiated $\mathrm{CaF}_{2}$ samples, are considered as most probable candidates. Hence, one should take into account thermal stability of $F$ centres. Most probably electron is released from $F$-centre during heating and the following X-ray irradiation causes the electron trapping again. It is in agreement with the observation that the reference non-irradiated material, which does not contain $F$ centres, does not change its colour in X-ray beam. These processes (electron releasing and trapping) can also explain the $\mathrm{E}_{6}$ emission band and its disappearance due to annealing. 


\subsection{TEM}

Samples of high- and low-irradiated fluorite and the reference sample of synthetic $\mathrm{CaF}_{2}$ were investigated by TEM. The TEM-EDS analysis showed no mutual intersample chemical differences within the instrument limits. Increasing defect concentration depending on radiation source activity was observed. The reference material showed no defects observable by TEM. However, in the low irradiated samples from Vlastějovice the dislocation loops are documented (Fig. 13 A). It is in a good agreement with results of previous studies [3]. The Kletno sample contains unexpectedly high density of defects as illustrated in the weak-beam dark-field image shown in Fig. 13 B. The dislocation density is so high in this case that it makes almost impossible to distinguish individual dislocations or dislocation-loops. The highresolution TEM image (Fig. 14) also confirms the presence of Ca inclusions, previously reported from irradiated samples, e.g., by [30]. These inclusions are produced by $F$-centres clustering and they represent stable void-superlattice. However, the Ca inclusions are not present in the low-irradiated sample. This is probably due to different activities of radiation source.

\section{Conclusions}

The present study characterizes $\mathrm{CaF}_{2}$ structure with a high density of radiation-induced defects created by long-time irradiation (in order of million of years) that causes significant lattice micro-strains whereas some previous studies (e.g. [2]) expected only low lattice strains and consequently also suggested $\mathrm{CaF}_{2}$ as a candidate for the containment of radioactive waste. These micro-strains decrease rapidly during heating to temperatures exceeding $300^{\circ} \mathrm{C}$. However the domain-size broadening was not observed. It was also shown that even after annealing some defects remain present in the structure (documented by non-zero strain observed by XRD or by PL spectra). The first principles PAS calculations showed that 
agglomerates of F-vacancies are detectable by PAS if they contain at least 4 F-

vacancies. Lifetime of positrons trapped at F-vacancy agglomerates depends on size

of the agglomerate and falls in the range from 190 to 302 ps. The presented positron

lifetime spectroscopic study have not been performed so far and substantially helped

to reveal the character of the defects and their behaviour. The detail measurements

showed the presence of $F$-centre agglomerates and their clustering during heating as

well as the $H$-centre clustering creating free fluorine bubbles in the structure. The

knowledge of these processes on the atomistic scale could be necessary for using

$\mathrm{CaF}_{2}$ as a material for high-resolution electron beam litography or as an insulating

layer for semiconductor technology as discussed in Ref. [5].

The defect-related emissions in PL spectra of irradiated $\mathrm{CaF}_{2}$ were discussed

in previous studies (e.g., [4]) without concrete assignment; as the results obtained

from other methods revealed the true character of the defects we were able to make

this assignment. The PL spectra also showed that the resistant defects are most

probably stabilized by impurities; this kind of defects could then significantly

influence the quality of optical devices mainly by causing decrease in transmittance.

Saturated positron trapping confirms a high-density of defects in irradiated $\mathrm{CaF}_{2}$,

which was documented also by TEM observations.

\section{Acknowledgement}

This work was funded by the The Ministry of Education of The Czech Republic (projects MSM0021620855 and MS0021620834). One of the authors (JV) acknowledges the support through the Centre of nanotechnology and materials for nanoelectronics, LC510 (funded by the MSMT CR). RS thanks for the support through the research plan AV0Z30130516 of the Institute of Geology AS CR.

\section{Literature}

[1] M. Boccanfuso, A. Benyagoub, M. Toulemonde, C. Trautmann, K. Schwartz, Ch. Dufour, Nucl Instr and Met in Phys Res B 175 - 177 (2001) p. 590 - 593

[2] L. T. Chadderton, Radiation Measurements 36 (2003) p. 13 - 34

[3] M. Watanabe, T. Noma, K. Yasuda, K. Yasunaga, S. Matsumura, C. Kinoshita, 16th International Microscopy Congress Abstracts (2006) 
[4] X. Xiang, X. T. Zu, S. Zhu, T. H. Ding, L. M. Wang, Opt Mat 28 (2006) p. 930 934

[5] T. Kogure, K. Saiki, M. Konno, T. Kamino, Mat Res Soc Symp Proc Vol 504 (1998) p. $183-188$

[6] H. P. Klug, L. E. Alexander, X-Ray Diffraction Procedures, Wiley, New York, 2nd edn. 1974

[7] F. Bečvář, J. Č́ížek, I. Procházka, and J. Janotová, Nucl. Instrum. Methods A 539 (2005) 372

[8] F. Bečvář, J. Čížek, and I. Procházka, Appl. Surf. Sci. 255 (2008) 111

[9] F. Bečvár, Nucl. Instrum. Methods B 261 (2007) 871

[10] I. Procházka, I. Novotný, and F. Bečvár, Mater. Sci. Forum 255-257 (1997) 772

[11] J. Č́ížek, I. Procházka, B. Smola, I. Stulíková, R. Kužel, Z. Matěj, and V. Cherkaska, Phys. Stat. Sol. (a) 203 (2006) 466

[12] M.J. Puska and R.M. Nieminen, J. Phys. F: Met. Phys. 13 (1983) 333

[13] E. Boroński, R.M. Nieminen, Phys. Rev. B 34 (1986) 3820

[14] M.J. Puska, S. Mäkinen, M. Manninen, and R.M. Nieminen Phys. Rev. B 39 (1989) 7666

[15] S.K. Dickinson, Infrared laser windows materials property data for $\mathrm{ZnSe}, \mathrm{KCl}$, $\mathrm{NaCl}, \mathrm{CaF}_{2}, \mathrm{SrF}_{2}, \mathrm{BaF}_{2}$, Air Force Cambridge Res. Lab. Report AFCRL-TR75-0318 (1975)

[16] R. W. G. Wyckoff, Crystal Structures, 9th ed., vol. 1, Interscience/John Wiley, New York, 1963

[17] M. Alatalo, B. Barbiellini, M. Hakala, H. Kauppinen, T. Korhonen, M. J. Puska, K. Saarinen, P. Hautojärvi, and R. M. Nieminen, Phys. Rev. B 54 (1996) 2397

[18] J. Kuriplach, A. L. Morales, C. Dauwe, D. Segers, and M. Šob, Phys. Rev. B 58 (1998) 10475

[19] B. Barbiellini, M. J. Puska, T. Torsti, and R. M. Nieminen, Phys. Rev. B 51 (1995) 7341

[20] B. Barbiellini, M. J. Puska, T. Korhonen, A. Harju, T. Torsti, and R. M. Nieminen, Phys. Rev. B 53 (1996) 16201

[21] M. Wojdyr, Fityk A curve fitting and data analysis program, software available at http://www.unipress.waw.pl/fityk/

[22] E. Johnson, and L. T. Chadderton, Micron 2 (1980) 247-250

[23] E. Johnson, L.T. Chadderton, Radiat. Effects 79 (1983) 183

[24] R. Bebbewitz, D. Smith, Phys. Rev. B 59 (1999) 8237

[25] L. P. Cramer, S. C. Langford, and J. T. Dickinson, J. Appl. Phys. 99, 054305 (2006)

[26] R. West, in Positrons in Solids, edited by P. Hautojärvi (Springer-Verlag, Berlin, 1979), p. 89.

[27] W. Brandt, G. Coussot, Paulin R., Phys. Rev. Lett. 23, (1969) p. 522 - 524

[28] E. Radzhabov, J. Phys. Condens. Matter 6 (1994) p. 9807-9815

[29] Z. Hao, J. Cai, L. Yi, J. Lum. 40\&41 (1988) p. 393 - 394

[30] L. T. Chadderton, E. Johnson, T. Wohlenberg, Physica Scripta Vol. 13 (1976) p. $127-128$ 
Table 1. Results of the first principles calculations of positron parameters (positron lifetime $\tau$ and positron binding energy to defect $E_{B}$ ) for various positron states in $\mathrm{CaF}_{2}$.

\begin{tabular}{|l|l|l|}
\hline & $\tau(\mathrm{ps})$ & $E_{B}(\mathrm{eV})$ \\
\hline bulk & 171.5 & - \\
\hline F-vacancy & 172.1 & 0.008 \\
\hline Ca-vacancy & 225.9 & 1.680 \\
\hline
\end{tabular}


Table 2. Results of positron lifetime measurements of $\mathrm{CaF}_{2}$ powders.

\begin{tabular}{|l|l|l|l|l|}
\hline Sample & $\tau_{1}(\mathrm{ps})$ & $I_{1}(\%)$ & $\tau_{2}(\mathrm{ps})$ & $I_{2}(\%)$ \\
\hline $\begin{array}{l}\text { reference, } \\
\text { non-irradiated }\end{array}$ & $110 \pm 10$ & $41 \pm 1$ & $322 \pm 2$ & $59 \pm 1$ \\
\hline irradiated, Kletno & $197 \pm 1$ & $67 \pm 1$ & $335 \pm 4$ & $33 \pm 1$ \\
\hline
\end{tabular}


Table 3. Observed emission bands and their assignment.

\begin{tabular}{|c|c|l|}
\hline Emission & $\lambda(\mathrm{nm})$ & \multicolumn{1}{|c|}{ Assignment } \\
\hline $\mathrm{E}_{1}$ & 431 & F-centres bound to substituent \\
$\mathrm{E}_{2}$ & 479 & non-radiation-induced defects \\
$\mathrm{E}_{3}$ & 514 & F-centres bound to substituent \\
$\mathrm{E}_{4}$ & 587 & F- / H- centres \\
$\mathrm{E}_{5}$ & 644 & non-radiation-induced defects \\
$\mathrm{E}_{6}$ & 720 & electron-defect bound state \\
\hline
\end{tabular}




\section{Figure captions}

Fig. 1 Williamson-Hall plot showing the data obtained through whole powder pattern fitting. The source powder patterns were measured in-situ during annealing. The micro-strain is proportional to the slope of the linear regression.

Fig. 2 Calculated positron density in (110) plane for (A) a perfect $\mathrm{CaF}_{2}$ crystal, (B)

$\mathrm{CaF}_{2}$ crystal containing F-vacancy, and $(\mathrm{C}) \mathrm{CaF}_{2}$ crystal containing Ca-vacancy.

Positron density is expressed in atomic units; distances are shown in units of $\mathrm{CaF}_{2}$ lattice parameter.

Fig. 3 Results of first principle calculations of positron parameters for F-vacancy agglomerates: (A) positron lifetime and (B) positron binding energy as a function of number of F-vacancies in the agglomerate. Dashed lines show positron parameters for a perfect $\mathrm{CaF}_{2}$ crystal, dash-doted lines show positron parameters for Ca-vacancy and dotted lines show positron parameters for a large fluorine void.

Fig. 4 Calculated positron density in (110) plane for a $\mathrm{CaF}_{2}$ crystal containing (A) Fdivacancy, (B) F-tetravacancy. Positron density is expressed in atomic units; distances are shown in units of $\mathrm{CaF}_{2}$ lattice parameter.

Fig. 5 Calculated positron density in (110) plane for a $\mathrm{CaF}_{2}$ crystal containing (A) an agglomerate of 8 F-vacancies, (b) a large fluorine void. Positron density is expressed in atomic units; distances are shown in units of $\mathrm{CaF}_{2}$ lattice parameter.

Fig. 6 Temperature dependence of the mean positron lifetime $\tau_{\text {mean }}$ for naturally irradiated $\mathrm{CaF}_{2}$ powder from Kletno.

Fig. 7 Temperature dependence of (A) lifetimes $\tau_{1}, \tau_{2}$ of exponential components resolved in positron-lifetime spectrum, (B) the relative intensity $I_{l}$ of the shorter component. Results measured on naturally irradiated $\mathrm{CaF}_{2}$ powder from Kletno are 
plotted by circles, while squares show results for the reference non-irradiated $\mathrm{CaF}_{2}$ powder. Position of the bulk $\mathrm{CaF}_{2}$ lifetime is indicated by the dashed line in the upper panel. The inset presents zoomed temperature dependence of the lifetime $\tau_{l}$.

Fig. 8 Experimental Doppler broadened annihilation profiles for non-irradiated $\mathrm{CaF}_{2}$ powder and well-annealed pure $\mathrm{Mg}$ reference sample compared with calculated HMP curves for perfect $\mathrm{Mg}$ and $\mathrm{CaF}_{2}$ crystal. Solid and dashed lines show the HMP curves calculated using GGA and LDA approach, respectively.

Fig. 9 The calculated HMP curve for a perfect $\mathrm{CaF}_{2}$ crystal with contributions of various core electron orbitals shown. The HMP curve was calculated using GGA approach. The partial contributions of Ca- and F-electrons are plotted by solid and dashed lines, respectively. Total contributions of positrons annihilated by Ca- and Felectrons are plotted in the figure as well.

Fig. 10 (A) Experimental CDB ratio curves (related to pure $\mathrm{Mg}$ reference sample) for virgin, non-irradiated $\mathrm{CaF}_{2}$ powder and for naturally irradiated $\mathrm{CaF}_{2}$ from Kletno. The latter sample was measured in the as-received (irradiated) state and after annealing up to various temperatures. (B) A detail of the amplitude of the peak in CDB ratio curves located at momentum $p \approx\left(9 \times 10^{-3}\right) \mathrm{m}_{0} \mathrm{c}$.

Fig. 11 Calculated ratio curves (related to pure $\mathrm{Mg}$ ) for free positrons annihilating in a perfect $\mathrm{CaF}_{2}$ crystal (bulk) and positrons trapped at Ca-vacancy $\left(\mathrm{V}_{\mathrm{Ca}}\right)$, agglomerate of 4 F-vacancies $\left(\mathrm{V}_{\mathrm{F} 4}\right)$, and agglomerate of $8 \mathrm{~F}$-vacancies $\left(\mathrm{V}_{\mathrm{F} 8}\right)$. The ratio curves were calculated using GGA approach.

Fig. 12 Photoluminescence spectra of long-time irradiated $\mathrm{CaF}_{2}$ untreated $(\mathrm{A})$ and after annealing up to $450{ }^{\circ} \mathrm{C}(\mathrm{B})$. 
Fig. 13 Weak-beam dark-field TEM images with $g=022$ of low-irradiated sample from Vlastějovice showing dislocation loops (A) and high-irradiated sample from Kletno displays extreme dislocation density (B).

Fig. 14 HRTEM images of high-irradiated sample from Kletno (left) and detail of clustered $F$-centres, indicated by the arrow (right). Inset in the left image is a Fast Fourier Transform image from the squared area, which corresponding to the right image. 


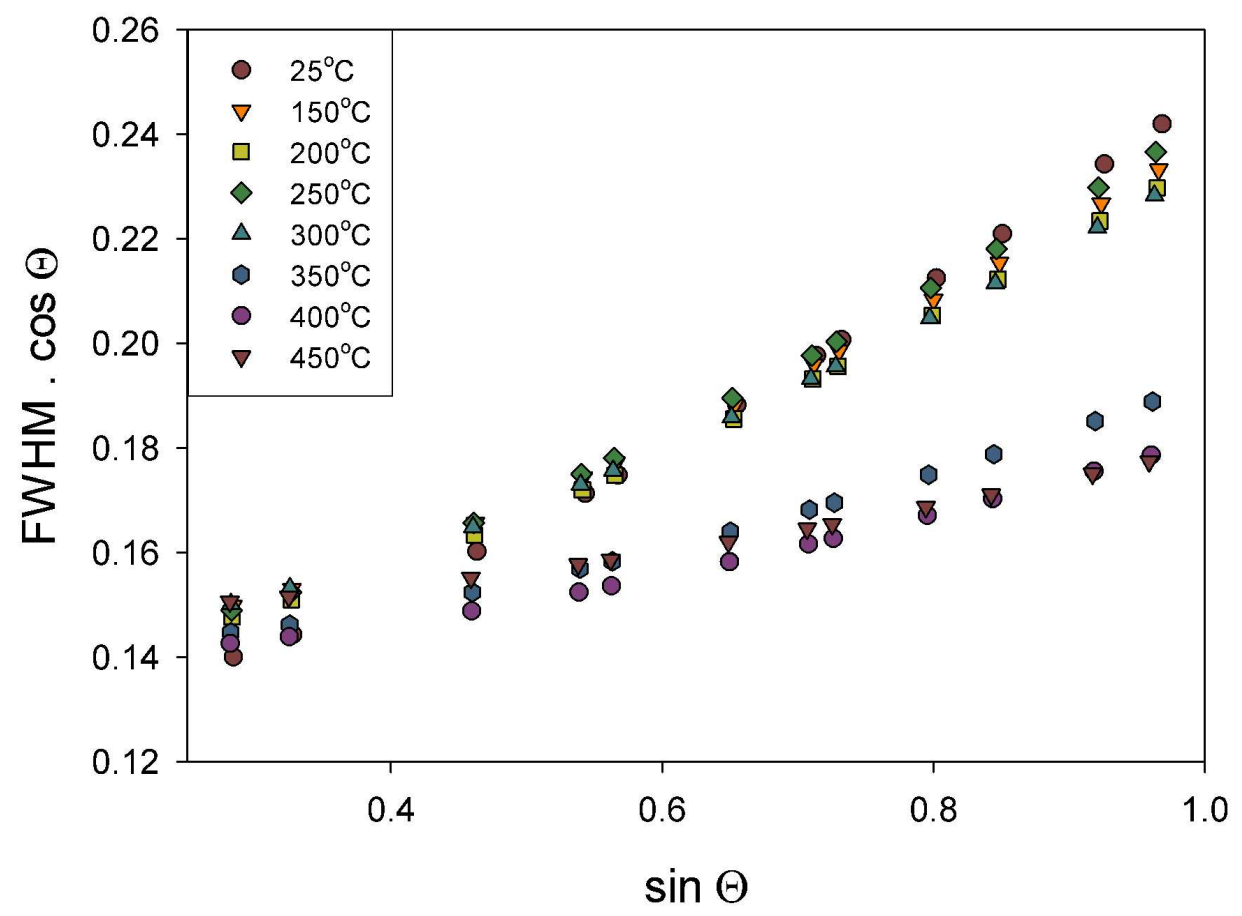

Williamson-Hall plot showing the data obtained through whole powder pattern fitting. The source powder patterns were measured in-situ during annealing. The micro-strain is proportional to the slope of the linear regression. $631 \times 486 \mathrm{~mm}(150 \times 150 \mathrm{DPI})$ 


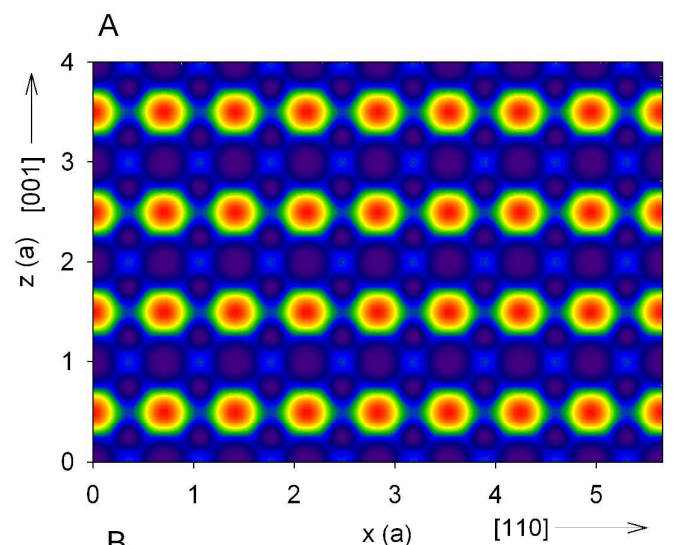

$$
\begin{aligned}
& 0.5 \times 10^{-5} \\
& 1.0 \times 10^{-5} \\
& 1.5 \times 10^{-5} \\
& 2.0 \times 10^{-5} \\
& 2.5 \times 10^{-5} \\
& 3.0 \times 10^{-5} \\
& 3.5 \times 10^{-5}
\end{aligned}
$$

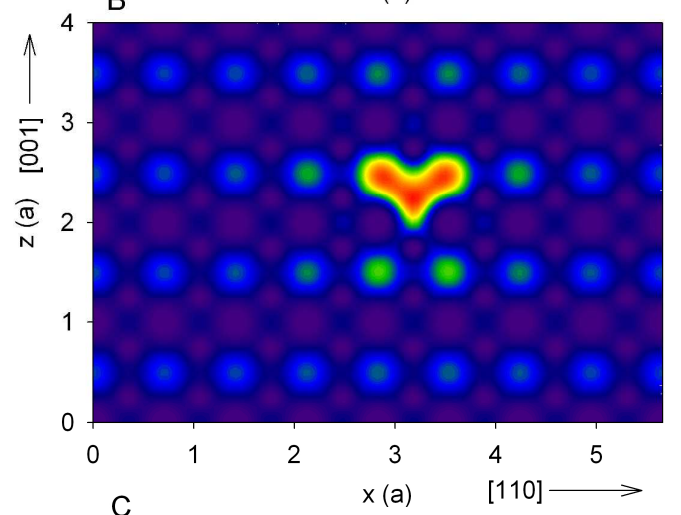

$$
\text { E } 1 \times 10^{-5}
$$

$$
\begin{array}{r}
2 \times 10^{-5} \\
3 \times 10^{-5}
\end{array}
$$$$
4 \times 10^{-5}
$$$$
5 \times 10^{-5}
$$$$
6 \times 10^{-5}
$$$$
7 \times 10^{-5}
$$$$
8 \times 10^{-5}
$$
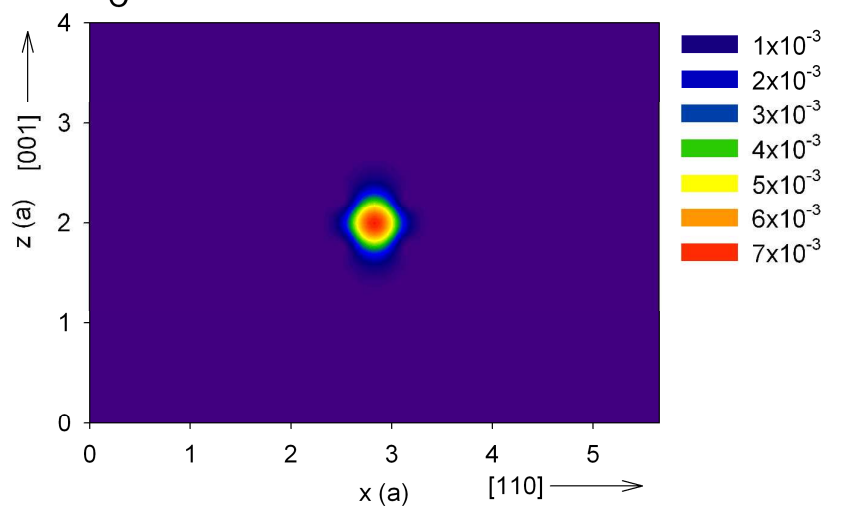

Calculated positron density in (110) plane for (A) a perfect CaF2 crystal, (B) CaF2 crystal containing F-vacancy, and (C) CaF2 crystal containing Ca-vacancy. Positron density is expressed in atomic units; distances are shown in units of CaF2 lattice parameter. $499 \times 877 \mathrm{~mm}(150 \times 150 \mathrm{DPI})$ 
Results of first principle calculations of positron parameters for F-vacancy agglomerates: $(A)$ positron lifetime and (B) positron binding energy as a function of number of F-vacancies in the agglomerate. Dashed lines show positron parameters for a perfect CaF2 crystal, dash-doted lines show positron parameters for Ca-vacancy and dotted lines show positron parameters for a large fluorine void.

$501 \times 778 \mathrm{~mm}(150 \times 150 \mathrm{DPI})$ 


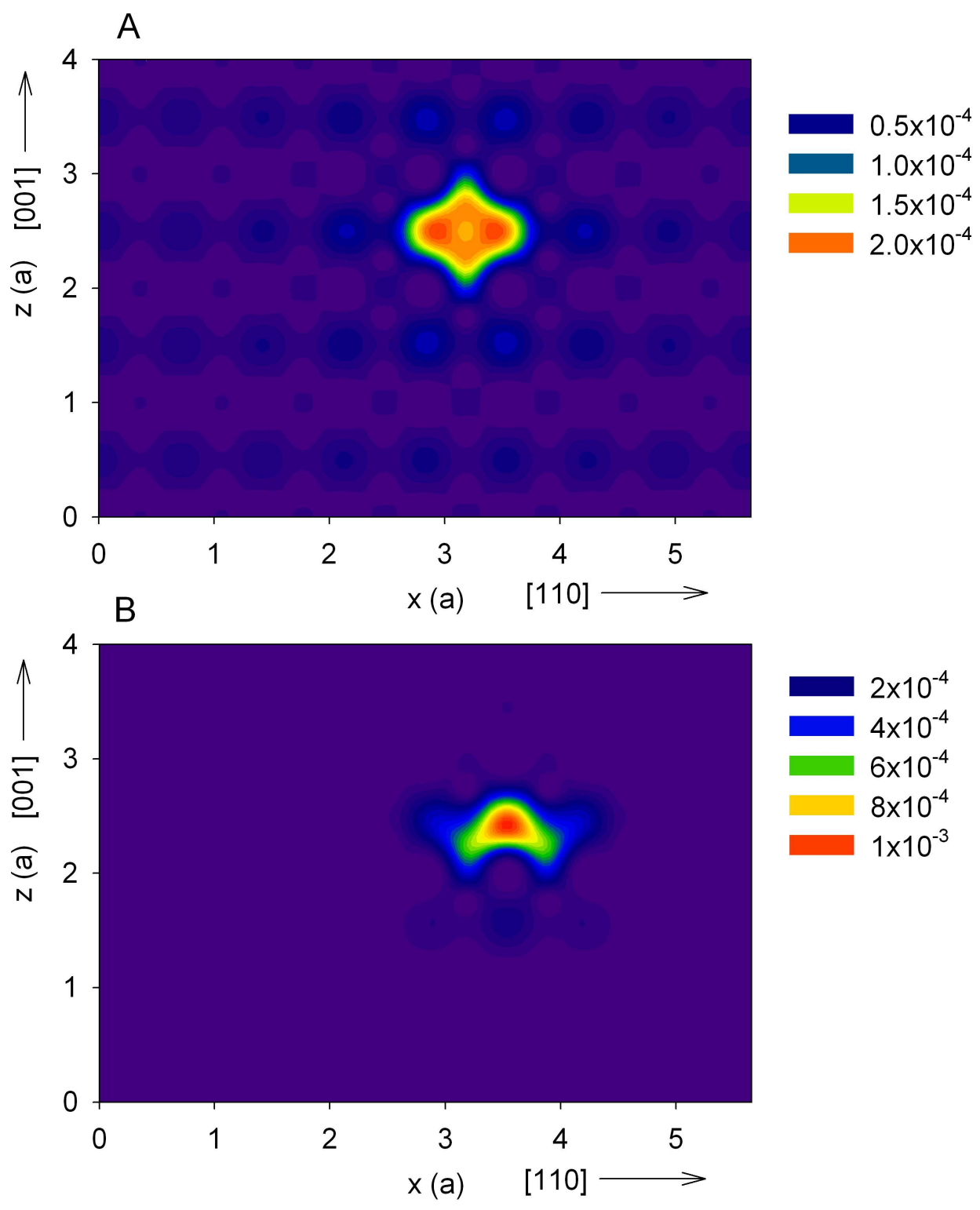

Calculated positron density in (110) plane for a CaF2 crystal containing (A) F-divacancy, (B) Ftetravacancy. Positron density is expressed in atomic units; distances are shown in units of CaF2 lattice parameter. $500 \times 594 \mathrm{~mm}(150 \times 150 \mathrm{DPI})$ 

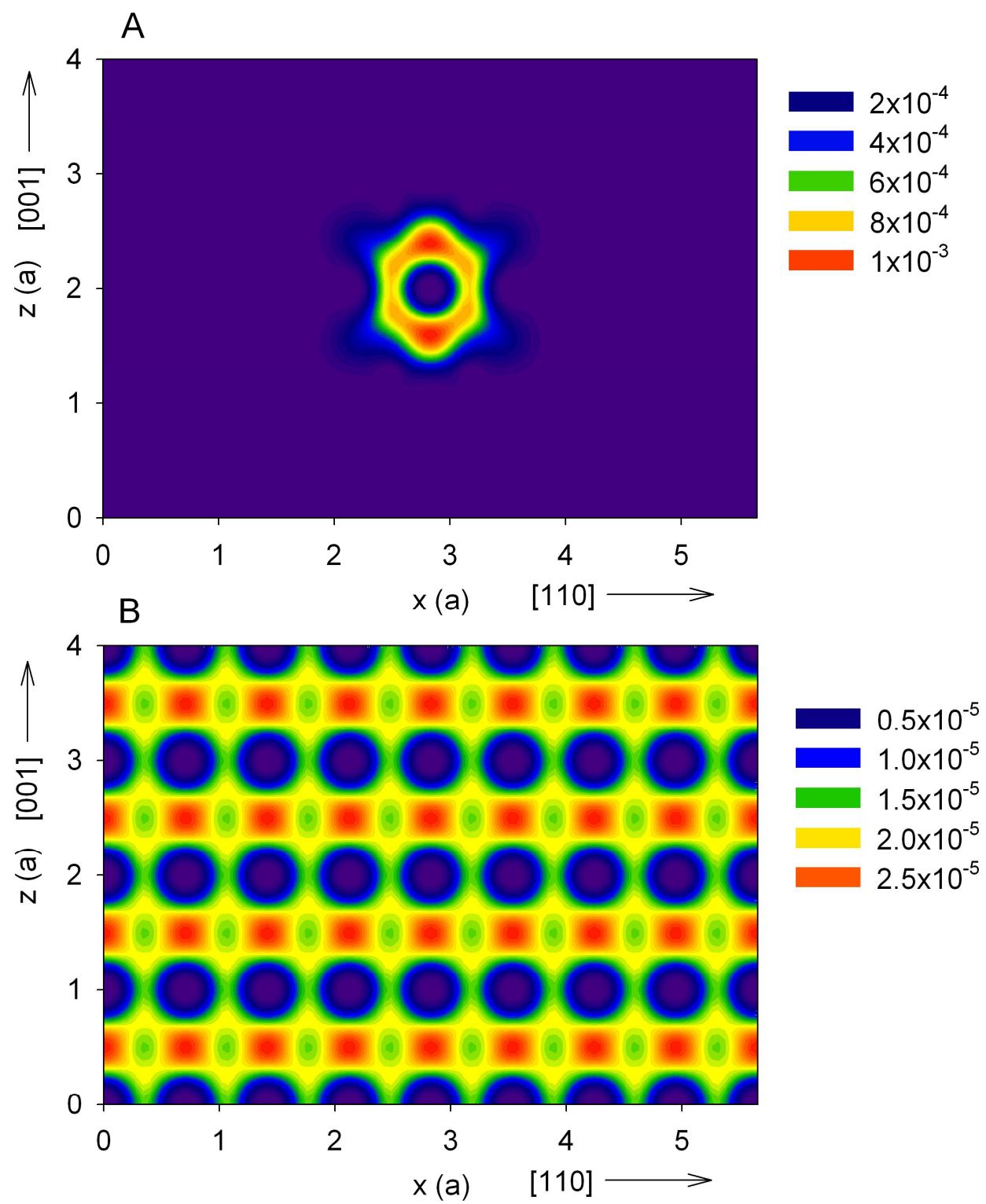

Calculated positron density in (110) plane for a CaF2 crystal containing (A) an agglomerate of $8 \mathrm{~F}-$ vacancies, (B) a large fluorine void. Positron density is expressed in atomic units; distances are shown in units of CaF2 lattice parameter. $501 \times 594 \mathrm{~mm}(150 \times 150 \mathrm{DPI})$ 


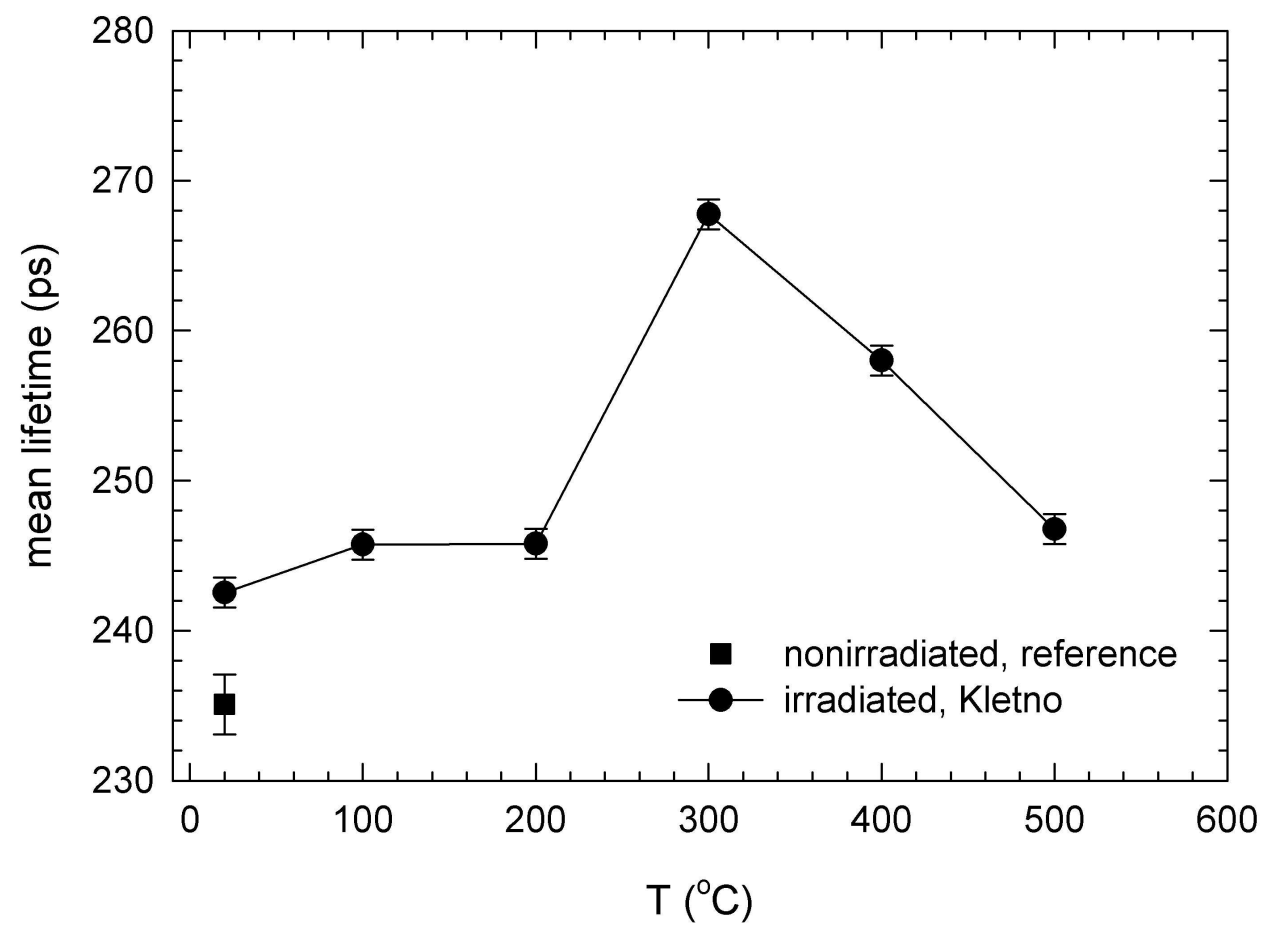

Temperature dependence of the mean positron lifetime tmean for naturally irradiated CaF2 powder from Kletno. $493 \times 397 \mathrm{~mm}(150 \times 150 \mathrm{DPI})$ 
Temperature dependence of $(A)$ lifetimes $T 1, T 2$ of exponential components resolved in positronlifetime spectrum, (B) the relative intensity I1 of the shorter component. Results measured on naturally irradiated CaF2 powder from Kletno are plotted by circles, while squares show results for the reference non-irradiated CaF2 powder. Position of the bulk CaF2 lifetime is indicated by the dashed line in the upper panel. The inset presents zoomed temperature dependence of the lifetime $\mathrm{T} 1$.

$711 \times 757 \mathrm{~mm}(150 \times 150 \mathrm{DPI})$ 


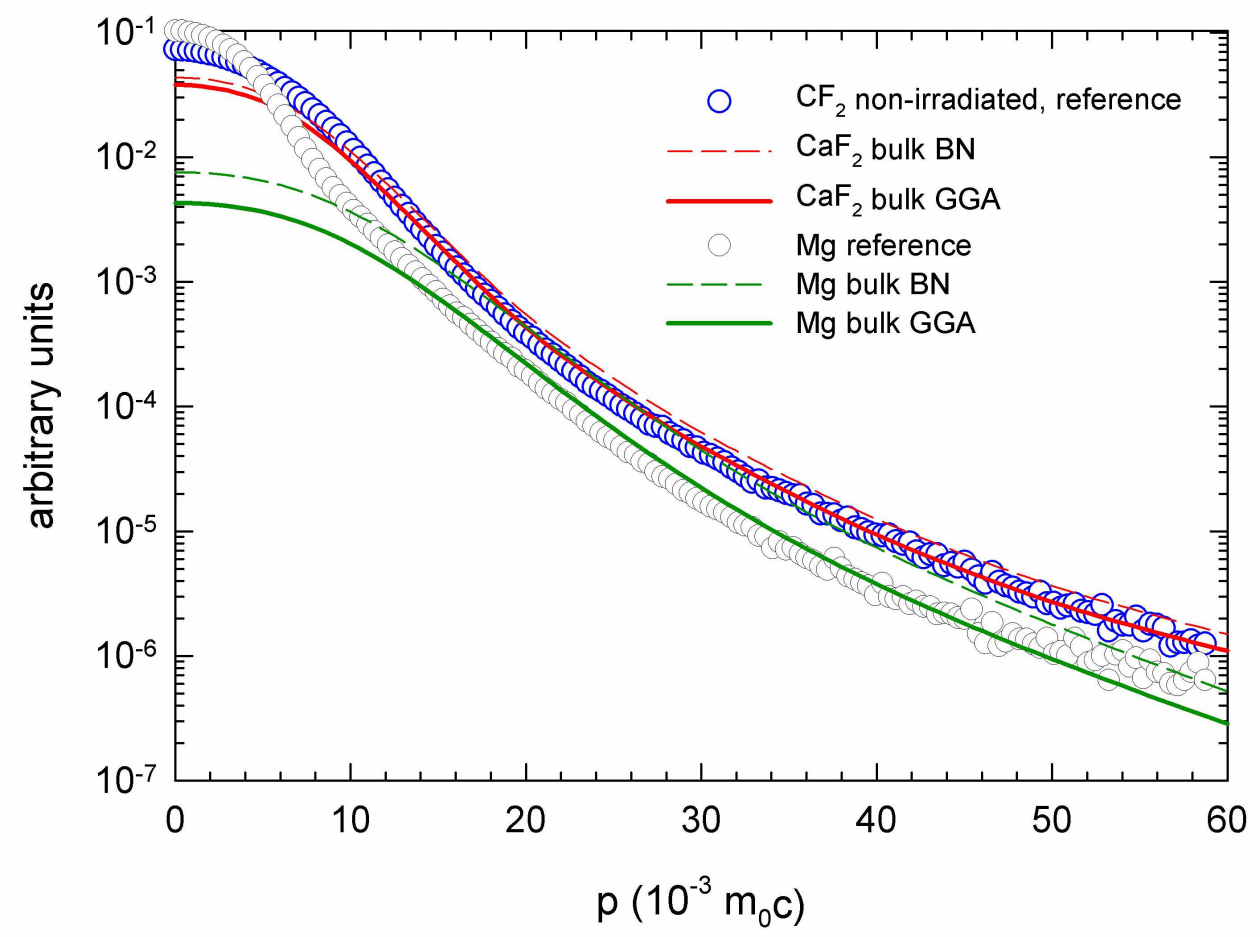

Experimental Doppler broadened annihilation profiles for non-irradiated CaF2 powder and wellannealed pure Mg reference sample compared with calculated HMP curves for perfect $\mathrm{Mg}$ and CaF2 crystal. Solid and dashed lines show the HMP curves calculated using GGA and LDA approach, respectively. $494 \times 402 \mathrm{~mm}(150 \times 150 \mathrm{DPI})$ 
The calculated HMP curve for a perfect CaF2 crystal with contributions of various core electron orbitals shown. The HMP curve was calculated using GGA approach. The partial contributions of Caand F-electrons are plotted by solid and dashed lines, respectively. Total contributions of positrons annihilated by $\mathrm{Ca}-$ and F-electrons are plotted in the figure as well. $710 \times 384 \mathrm{~mm}(150 \times 150 \mathrm{DPI})$ 


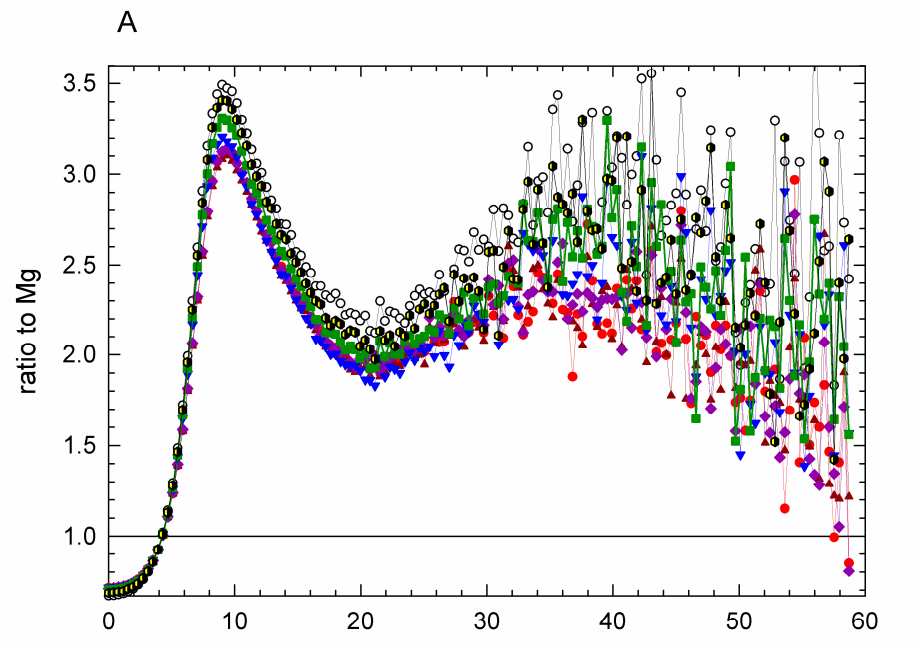

- nonirradiated, reference

- irradiated

- irradiated, annealed $100^{\circ} \mathrm{C} / 1 \mathrm{~h}$

- irradiated, annealed $200^{\circ} \mathrm{C} / 1 \mathrm{~h}$

- irradiated, annealed $300^{\circ} \mathrm{C} / 1 \mathrm{~h}$

- irradiated, annealed $400^{\circ} \mathrm{C} / 1 \mathrm{~h}$

- irradiated, annealed $500^{\circ} \mathrm{C} / 1 \mathrm{~h}$

B $\mathrm{p}\left(10^{-3} \mathrm{~m}_{0} \mathrm{c}\right)$

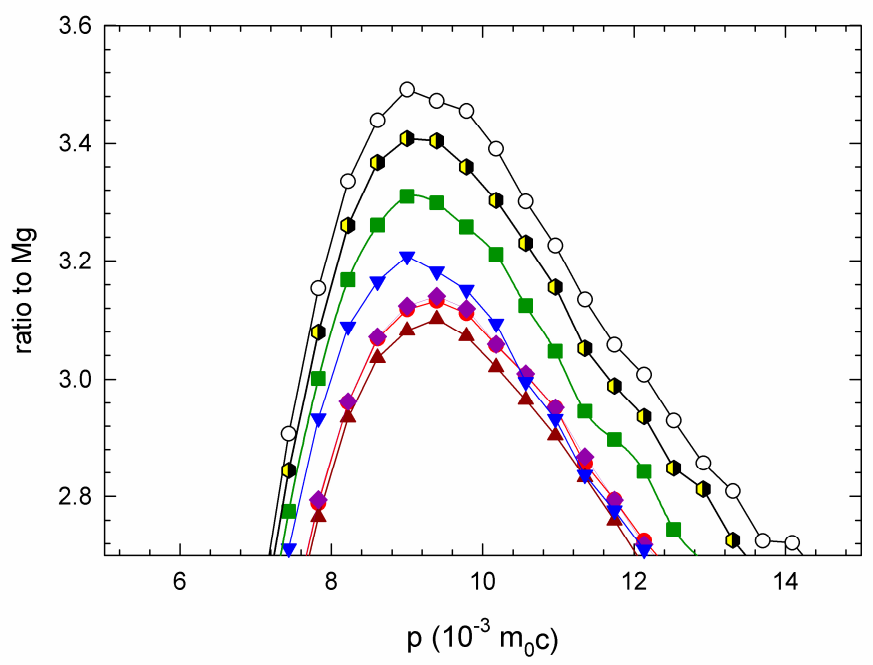

- - nonirradiated, reference - - irradiated

- irradiated, annealed $100^{\circ} \mathrm{C} / 1 \mathrm{~h}$

- irradiated, annealed $200^{\circ} \mathrm{C} / 1 \mathrm{~h}$ $\boldsymbol{\nabla}$ irradiated, annealed $300^{\circ} \mathrm{C} / 1 \mathrm{~h}$ $\rightarrow$ irradiated, annealed $400^{\circ} \mathrm{C} / 1 \mathrm{~h}$ - irradiated, annealed $500^{\circ} \mathrm{C} / 1 \mathrm{~h}$

(A) Experimental CDB ratio curves (related to pure Mg reference sample) for virgin, non-irradiated CaF2 powder and for naturally irradiated CaF2 from Kletno. The latter sample was measured in the as-received (irradiated) state and after annealing up to various temperatures. (B) A detail of the amplitude of the peak in CDB ratio curves located at momentum $p \approx(9 \times 10-3)$ m0c.

$751 \times 789 \mathrm{~mm}(150 \times 150 \mathrm{DPI})$ 


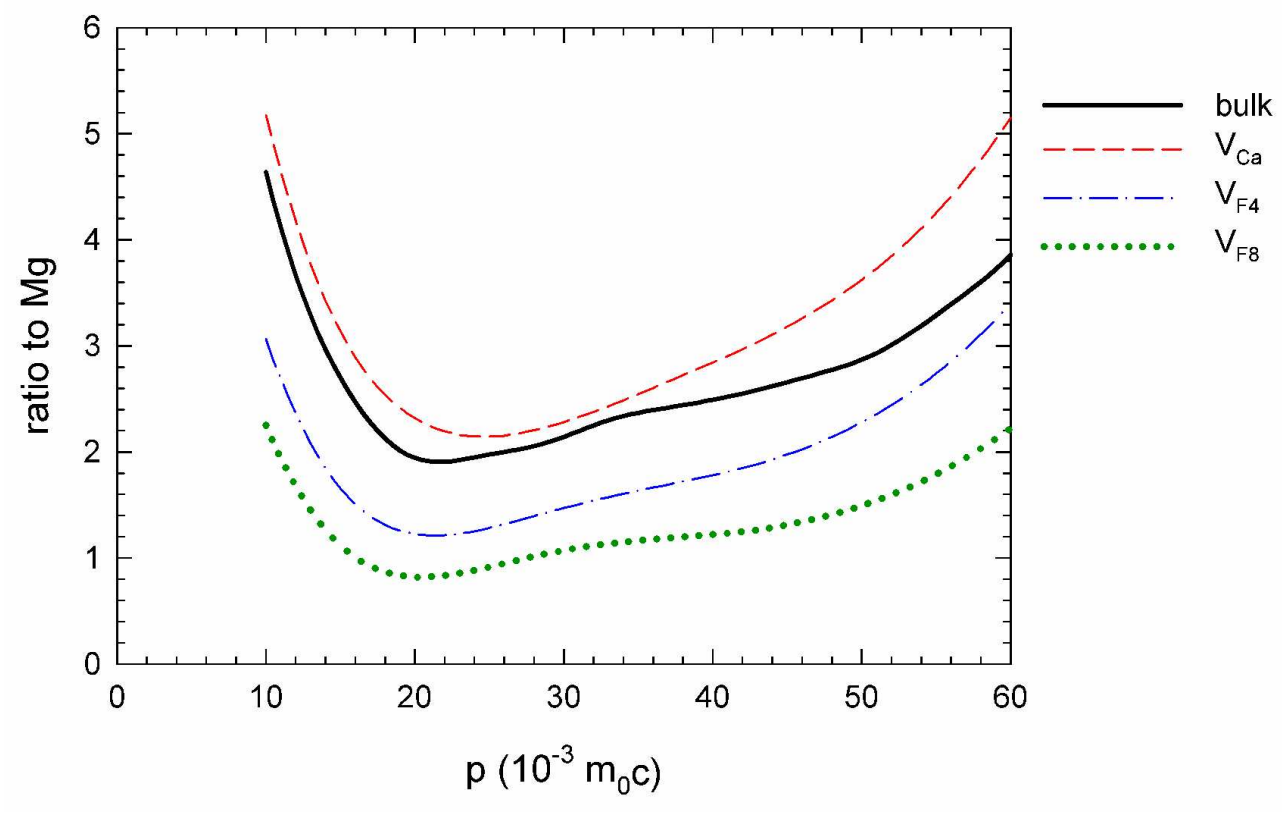

Calculated ratio curves (related to pure $\mathrm{Mg}$ ) for free positrons annihilating in a perfect CaF2 crystal (bulk) and positrons trapped at Ca-vacancy (VCa), agglomerate of 4 F-vacancies (VF4), and agglomerate of 8 F-vacancies (VF8). The ratio curves were calculated using GGA approach. $581 \times 405 \mathrm{~mm}(150 \times 150 \mathrm{DPI})$ 
Photoluminescence spectra of long-time irradiated CaF2 untreated (A) and after annealing up to 450 ${ }^{\circ} \mathrm{C}(\mathrm{B})$. $16 \times 10 \mathrm{~mm}(600 \times 600 \mathrm{DPI})$ 

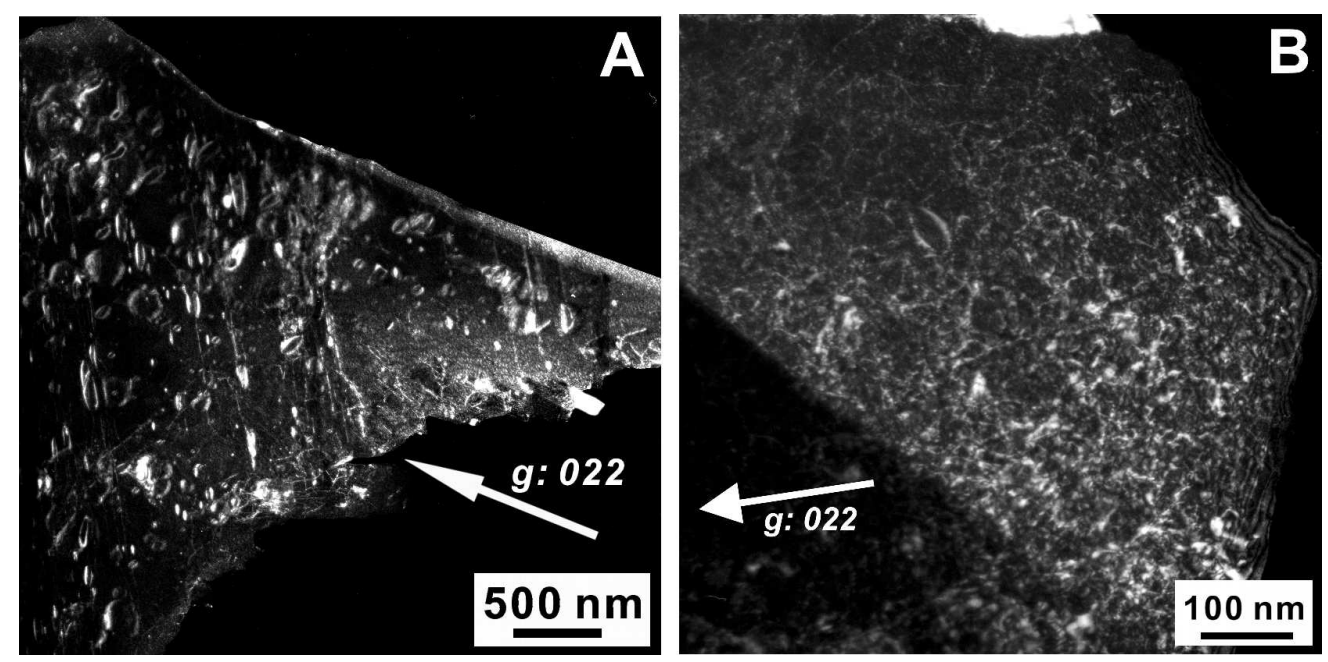

Weak-beam dark-field TEM images with $\mathrm{g}=022$ of low-irradiated sample from Vlastějovice showing dislocation loops (A) and high-irradiated sample from Kletno displays extreme dislocation density (B). $169 \times 83 \mathrm{~mm}(500 \times 500$ DPI $)$ 

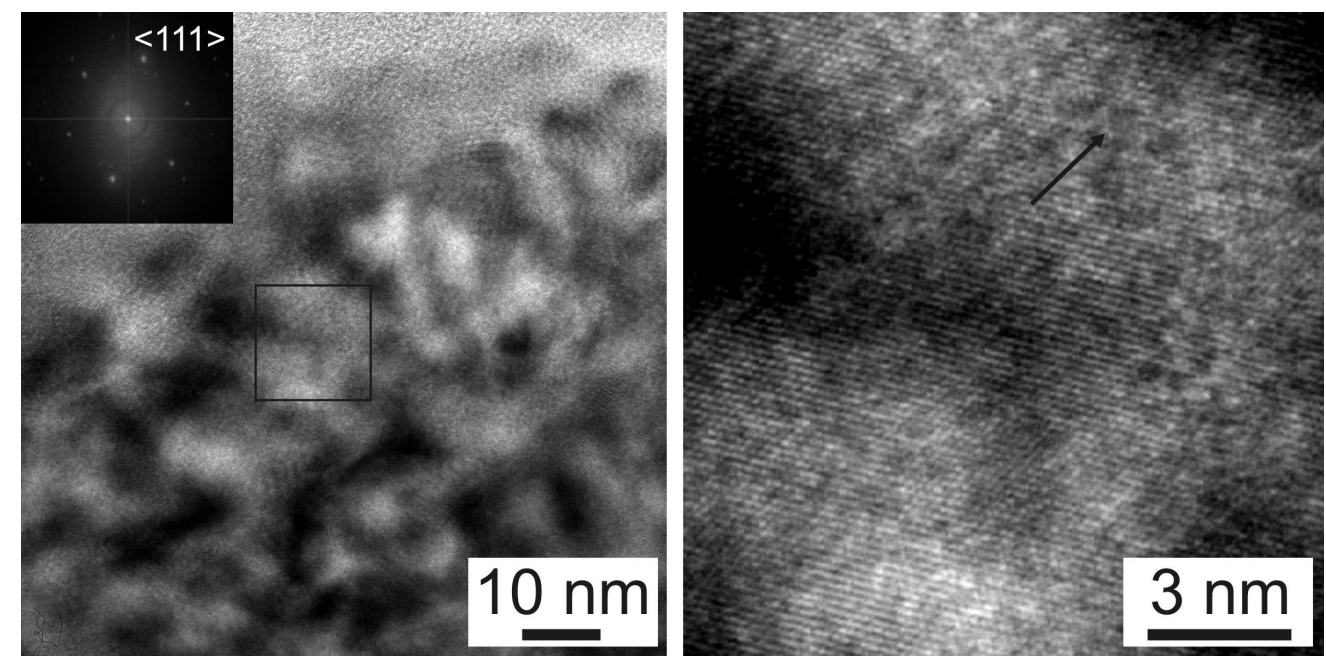

HRTEM images of high-irradiated sample from Kletno (left) and detail of clustered F-centres, indicated by the arrow (right). Inset in the left image is a Fast Fourier Transform image from the squared area, which corresponding to the right image. $100 \times 49 \mathrm{~mm}(600 \times 600 \mathrm{DPI})$ 